\title{
Prediction of Staff Performance in Clinical and Para-clinical Fields in Ahvaz Imam Khomeini Hospital Based on Happiness Components According to Fordyce Model
}

\author{
Farnaz Pishgar \\ Department of Management (Khorasgan) Branch, Islamic Azad University, Isfahan, Iran
}

\author{
Doi:10.5901/mjss.2015.v6n6s2p367
}

\begin{abstract}
The aim of the present study was to predict staff performance in clinic and Para-clinical fields of Ahvaz Imam Khomeini hospital based on happiness components according to Fordyce model. In this study, the descriptive research method was of the correlational type. Necessary information was prepared from selected sample from the research statistical population, namely clinic and Para-clinic staff of Ahvaz Imam Khomeini hospital who was 1000 ones and 280 of them was selected as volume of the sample based on Cochran formula using available sampling. Data were collected using a researcher-built happiness questionnaire based on Fordyce's 14-point model with 42 questions and performance questionnaire by Stephen E. Candrie with 10 aspects and 32 questions. Cronbach alpha coefficient for happiness questionnaire and performance questionnaire were 0.97 and 0.94 , respectively indicating acceptable reliability. Also, validity of the questionnaire was confirmed based on supervisors and number of experts in the field of management through content validity. Data analyses were done in to levels of descriptive and inferential statistics. In inferential part, a regression analysis was done using SPSS software. The results of the present study showed that the aspects of being more active, collective activity, reduced expectations, being optimistic, healthy personality, being own self, and social character of Ahvaz Imam Khomeini hospital staff are as predictor of their performance and with enhancement of collective activity up to 0.3 of a unit, the being optimistic, healthy personality, being more active, decreased expectations, being own self, and social character are increased up to $0.4,0.3,0.4,0.7,0.4$, and 0.3 of a unit, respectively.
\end{abstract}

Keywords: Organizational happiness, Performance, Performance management

\section{Introduction}

Happiness is the most fundamental human discussion for all generations and is the most canonical stimulus of human purposes. Plato in his book "Republic" refers to three elements in the human essence that are: wisdom or reasoning, emotions and wills. Plato knows happiness as a state of human that there is a balance and conformity among these three elements. Jan Rich (2002) believes that happiness is not only being aware about occurrence of good events in your life, but it is being aware about this issue that you oneself are the creator of these events. You are reason, creator, and controller of events; because you play a great role in good events occurred for you. You feel happy. The lowest level of happiness is being aware of this issue that you can prevent the occurrence of bad events. This feeling of dominance and control on good and bad events of the life aggregately creates a good feeling for you (Baseri, 2010). The happiness causes a positive attitude to life, positive imagination, having mental health and emotional balance, being hopeful to future, desire and satisfying attitude with respect to oneself and the others, balanced social communications, shirking from grudge and hate, selection of life purposes with aware, try to achieving purposes, shirking form time waste and laziness, enhancement of life successes, having high life indices, better performance of safety system against stress, better dream, more willing to help others and better decisions (Sharifi et al., 2010). Some researchers such as Alipour, Nourbala, Ezheie, and Motieian in 2000 stated this point that happiness improves safety system and safety system improvement tailors the health of the person (Pahlevan Sadegh and Bakhtiar Nasrabadi, 2009). Today, the advancement of every society depends on optimal use of human force of that society and it is one of the most important principles in the field of human force management, attention to happiness and happiness issue of humanity, because a happy human is an efficient, productive, and creative one and just these positive actions will greatly help his/her physical and mental health. It is noteworthy to be said in today world in which machine life has been prevailed and others do not pay attention to issues such as prank and making happiness and since managers' and leaders' spirits has had an effect on excitations of people around, thus, employees must melt available ice by making happiness and work beside colleagues with a pleasure feeling and employees feel calm from working in the environment and newcomers know themselves as a member in the group and when the manager is happy, thus, people around also see everything from a more positive 
window and increase their creativity and efficiency in order to improve organizational performance to prepare a field for being useful and effective people. By making advantages and the importance of a happy work environment obvious, various countries have paid special attention to this issue. In this basis, considering this issue in great policy making is very important. Enhancement of individual and social happiness is one of the purposes and priorities of many organizations and institutions. At a great level, officials and superior managers of various countries always try to act in laws and executive methods of their country in such a way to enhance happy and happiness among people continuously. Having happy and efficient employees is one of goals of organizational and industrial sets. One the most sensitive organizations in which organizational performance of its employees plays a fundamental role in health and life of the society is hospital. Despite conducted attempts in these centers, feeling the lack of organizational happiness can usually affect their organizational performance. Zarei Matin et al. (2009) based on their studies reported outcomes such as better mental health of employees under effect of creating a happy work environment. Studies done in abroad also show that people who are happier have more organizational commitment than the others (Boehm and Lyubomirsky, 2007). People who are happier show less job burnout than the others (Dutton and Edmund, 2007). They have less absence at their workplace and it is less possible than the others to leave their job (Boehm and Lyubomirsky, 2007). The present study aims to predict the staff performance in clinical and para-clinical fields of Ahvaz Imam Khomeini hospital based on happiness components according to Fordyce model.

\section{Research Background}

Suphaphun et al. (2014) in a research in Thailand studied 254 employees of Amata Nakorn Company. Their research was done using combinational method (Quantitative and Qualitative). In quantitative and qualitative sections, data were collected using researcher-built questionnaire and through observing, investigating the documents and interviewing, respectively. The results of their study showed that welfare and friendship are the main key for happiness at work environment. After investigating the ideas and suggestions of employees for creating happiness at workplace and the attitude of employees for the future of the organization, the happiness components at work environment were identified. The findings of this research were investigated both in individual and organizational level. Kalayanee and Anusorn (2014) in a research investigated the happiness in Thailand and studied the effect of family, health, and job satisfaction on people happiness. The results of their research showed that family plays a decisive role in people happiness. Also, three variables of family, health, and job satisfaction are as predictor of people happiness and these three variables were effective on people happiness in life. Proctor (2014) in a research investigated the effectiveness of organizational relations under the effect of staff attitude and their happiness and job satisfaction. He in this research reported that there was a bilateral relation among these variables. The employees who had better communicational skills and more desirable organizational relations had more job satisfaction and also more happiness at work environment. Also, the results showed that employees, who had better communicational skills, had more positive attitude. In 2002, Lee Bark and Stanly Tun conducted some controlled studies in the field of happiness, performance, and work stress of staff. The results of these studies showed that mental effects resulted from heart laughing act exactly in the reverse direction of mental stress so that some people knew laughing loudly for ten minutes as a equivalent for sleeping for two hours. In 2003, Die et al. conducted a research about identification of effective factors on staff employees in transportation companies in Australia. They concluded from their results that happiness among employees has been more effective on staff performance improvement than the other factors and has had more effect on productivity, efficiency, and finally performance of the organization. Zarei et al. in 2009 did a research about the identification of happiness components at work environment and assessing the status of these components in Qom executive organizations. Despite doing a literature survey and investigating the research background, they in their research recognized 10 components for the happiness at work place and according to these components they designed a questionnaire for assessing happiness at workplace. The results obtained from information analysis showed that in selected organizations in Qom the components of organizational learning, self-openness, participation, justice, optimism, and flexible structure were in an improper status and the components of meaningfulness of work, interest in work, safety at workplace, and interaction with colleague were in a medium level. Alipour and Erabi in 2011 conducted a research about the relation of hope and happiness with job satisfaction of employees in Tabas and selected and investigated 240 teachers based on sampling. The results of their research showed that both of hope and happiness have a relationship with job satisfaction as well as they have a relationship with each other. Totally, teachers who have more hope and happiness have higher job satisfaction score. 


\section{Theoretical Framework}

Happiness or happiness has been known as a combination of positive affection, absence of negative affection, and satisfaction from life. Joy is one of three types of happiness and cheerfulness. As it has been defined in Argyle's definition two other aspects happiness are satisfaction from life and absence of negative affection. Joy is the exciting aspect of happiness and satisfaction from life is its cognitive aspect. Fordyce's model includes following components:

\subsection{Being more active and entertainment}

Happy people spend their life with various activities and more important point is that the most of times they spend their time to do interesting and joyful activities (Luma, 2001).

\subsection{Spending more time in communities and social activities}

The active life is the most important factor of happiness. The studies have shown that the existence of social interactions has increased the feeling life satisfaction, having support from the others, and a sense of belonging to the group and consequently, all of these cases are very effective on creating and enhancement of happiness in people (Luma, 2001).

\subsection{Being generative and doing beneficial and intellectual things}

Happiness and life satisfaction have a relationship with meaningful and generative work. The investigations show that the happiest people are who enjoy from their work. The important point is attention to this that in today communities, people spend about 80 percent of their awakening time in their own workplace and therefore if they enjoy from their work and the job make them happy, it will be very effective on enhancement of their total happiness. People must always have a sense of more responsibility with respect to their commitment and purposes and try to not lose their goal to not feel lack of productivity and profitability (Luma, 2001).

\subsection{Better programming and organizing}

The studies show that people who are happier often have better programming and organizing in their works. They are efficient and do not postpone affairs. Despite being effective in daily affairs, organizing also has a significant effect on long-term programs (Luma, 2001).

\subsection{Distance anxieties}

Happy people become less concerned. Fordyce in his training program introduced anxiety and concern as number one enemy for happiness. In this stage of training, learners learn to spend more free time for joyful activities and control negative thoughts (Luma, 2001).

\subsection{Decrease expectations and wishes}

Daily expectations and long-term successes play an important role in people happiness. Very high expectations usually result in frustration and failure but lower expectations usually result in desirable outcomes. Happy people tend to select goals in their life that have ability to achieve them. Therefore, they achieve whatever they want. Happiness is obtained by achieving achievable goals not in failure in imaginary ones (Luma, 2001).

\subsection{Increase positive thoughts and optimism}

Happiness affects on the process of creating happiness through various ways and optimism is interpretation and positive understanding of events. Happiness is not resulted from having something but depends on individual view with respect to that thing (Luma, 2001). 


\subsection{Living at the present time}

Happy people always pay attention to the present time and try to get maximum pleasure from their daily activities according to their facilities. Happy people enjoy their life more than unhappy ones because they do not focus on bitter events of the past and do not feel sorrow about doing some affairs (Luma, 2001).

\subsection{Training perfect character}

The fundamental principles of mental health include loving, self-acceptance, self-knowledge, and self-help and the existence of happiness in life depends on the right decisions. Earth human can decide correctly to recognize own self and determine does he/she has necessary ability for successful implementation of the decision (Luma, 2001).

\subsection{0}

Educating social and extrovert character

People are happier who enjoy an active social life. So Fordyce knows being social and extroversion as the most important way to happiness (Luma, 2001). .

\subsection{Having self-confidence}

Other features of happy people are self-motivation and being natural that cause comfort in daily life and that when a person accepts his/herself as he/she is and express honestly things progress largely according to his/her desire (Luma, 2001).

\subsection{Eradicating negative feelings and problems}

People with anxiety, emotional problems, and addiction should try to eliminate these issues to become a happy person (Luma, 2001).

\subsection{Intimate and close relation}

The importance of close contact with friends, family and romantic relationships should be considered and doing them is strongly recommended (Luma, 2001).

\subsection{Prioritizing and valuing happiness}

Happy people know happiness as the most important thing in their life and the achieving the happiness depends on how much a person wants to be happy and how important being happy is for him (Luma, 2001). 


\section{Conceptual Model of the Research}

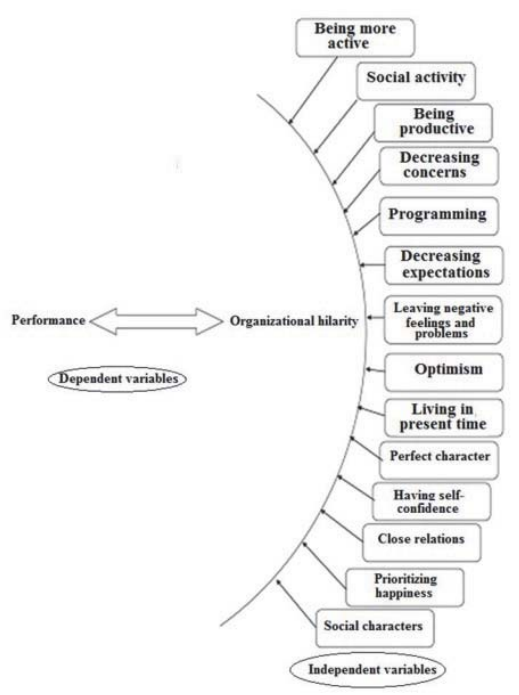

\section{Method}

This research is descriptive of the correlational type. It is descriptive because it studies happiness and performance in Ahvaz Imam Khomeini Hospital in the present conditions and it is correlational because it aims to study the relation between happiness and organizational performance. The statistical population of the present research is all clinical and para-clinical staff in Ahvaz Imam Khomeini Hospital that according to the selection of Hospital was 1000 persons. 280 of them were studied based on Cochran formula. In this study, two questionnaires were used to collect data and information. Staff happiness questionnaire was developed by researcher and based on Fordyce model indices. Totally, 42 questions were prepared based on Fordyce's 14 fundamentals. This questionnaire was prepared based on 5-point Likert scale (very low, low, medium, high, and very high). The lowest and the highest score for items of questionnaire was 1 and 5, respectively. A high score in this questionnaire shows more happiness among staff. Staff performance questionnaire evaluated 10 dimensions using 32 questions. Each question had three options (beyond expected, as expected, needs improvement). In each question, the score for selection of "beyond expected", "as expected", and "needs improvement" was 3, 2, and 1 respectively. If staff score was 64 to 96, their performance was "beyond expected"; if staff score was 32 to 64, their performance was "as expected"; if staff score was lower than 32, their performance needed programming for improvement. In this study, face and content validity were used to investigate the validity of questionnaires. Therefore, after developing the questionnaire, each of questions was investigated by experts for the purpose of determining connection of items with the variable under assessment. After doing investigations, improper and obscure items were eliminated or moderated. The validity assessment or repeatability of questionnaire items also done using Cronbach alpha that it was for happiness questionnaire 0.973 and 0.945 for performance questionnaire indicating acceptable validity of the research questionnaire. The method of information analysis in this research is both descriptive and inferential. Average descriptive statistics, standard deviation, frequency, and percentage were used in descriptive section of data and information analysis. Regression analysis using SPSS software was used in inferential section due to determining the prediction of staff performance based on happiness components according to Fordyce's model.

\section{Findings}

\subsection{Demographic description}

$59 \%$ of respondents were women with the frequency of 166 and $41 \%$ of them were men with the frequency of $114.70 \%$ of respondents were married with the frequency of 196 and $30 \%$ of them were single with the frequency of 84 . The highest percentage and frequency was related to people with Bachelor of Science (118 persons with $42.1 \%$ of statistical 
population) and the lowest percentage and frequency was related to people with Master of Science (29 persons with $10.4 \%$ of statistical population) and diploma (28 persons with $10 \%$ of statistical population).

\subsection{Describing happiness and happiness and their aspects}

Data obtained from organizational happiness questionnaire among Ahvaz Imam Khomeini Hospital employees that show frequency distribution of respondents in terms of happiness and happiness are given in Table 1.

Table 1. Distribution of respondents in terms of total happiness and happiness

\begin{tabular}{|l|c|c|c|c|}
\hline & Frequency & Percentage & Percentage of validity & The cumulative percentage \\
\hline Very low & 12 & 4.3 & 4.3 & 4.3 \\
\hline Low & 7 & 2.5 & 2.5 & 6.8 \\
\hline Medium & 100 & 35.7 & 35.7 & 42.5 \\
\hline High & 104 & 37.1 & 37.1 & 79.6 \\
\hline Very high & 57 & 20.4 & 20.4 & 100.0 \\
\hline Total & 280 & 100.0 & 100.0 & \\
\hline
\end{tabular}

As shown in Table 1, happiness and happiness of $57 \%$ of respondents are high and very high and happiness and happiness of $7 \%$ of them are low and very low.

Table 2. Descriptive indices of total happiness and happiness

\begin{tabular}{|l|c|c|c|c|c|}
\hline & Number & Minimum & Maximum & Average & Standard deviation \\
\hline Total happiness and happiness & 280 & 50 & 196 & 156.92 & 34.477 \\
\hline
\end{tabular}

As it is clear from Table 2, the average of happiness and happiness aspects of employees is 156.92 out of 210. Also, adapted data in terms of each of happiness and happiness aspects for Ahvaz Imam Khomeini Hospital employees have been presented as follows:

Table 3. Descriptive indices of happiness components based on Fordyce model

\begin{tabular}{|l|c|c|c|c|c|}
\hline & Number & Minimum & Maximum & Average & Standard deviation \\
\hline Being more active & 280 & 3 & 15 & 11.74 & 2.956 \\
\hline Social activity & 280 & 3 & 14 & 10.66 & 2.903 \\
\hline Being productive & 280 & 3 & 15 & 11.55 & 3.211 \\
\hline Programming & 280 & 3 & 15 & 11.45 & 3.119 \\
\hline Removing concerns & 280 & 3 & 15 & 10.53 & 3.185 \\
\hline Decreasing expectation & 280 & 2 & 15 & 11.16 & 3.092 \\
\hline Optimism & 280 & 3 & 15 & 11.55 & 3.035 \\
\hline Living in the present time & 280 & 3 & 14 & 10.80 & 2.698 \\
\hline Perfect character & 280 & 5 & 15 & 11.69 & 2.296 \\
\hline Having self-confidence & 280 & 4 & 15 & 11.78 & 3.065 \\
\hline Close communications & 280 & 3 & 15 & 10.24 & 3.286 \\
\hline Prioritizing happiness & 280 & 3 & 15 & 12.41 & 3.006 \\
\hline Social character & 280 & 3 & 14 & 10.60 & 2.690 \\
\hline Leaving aside negative feelings & 280 & 3 & 15 & 10.77 & 3.359 \\
\hline
\end{tabular}

As shown in Table 3, the average of the earned score of employees in aspect of leaving aside negative feelings is 10.77.

\subsection{Description of performance and its aspects}

The description of total performance and its aspects, data obtained from staff performance questionnaire in Ahvaz Imam Khomeini Hospital based on determined performance aspects are presented in following Table in three scopes of "beyond expected", "as expected", and "need improvement": 
Table 4. Distribution of respondents in terms of total performance

\begin{tabular}{|l|c|c|c|c|}
\hline & Frequency & Percentage & Percentage of validity & The cumulative percentage \\
\hline As expected & 3 & 1.1 & 1.1 & 1.1 \\
\hline Beyond expected & 277 & 98.9 & 98.9 & 100.1 \\
\hline Total & 280 & 100.0 & 100.0 & \\
\hline
\end{tabular}

As it is observed from Table 4, total performance of $99 \%$ of respondents with a frequency of 277 is "beyond expected" and total performance of $1 \%$ of them with a frequency of 3 is "as expected".

Table 5. Descriptive indices of performance

\begin{tabular}{|l|c|c|c|c|c|}
\hline & Number & Minimum & Maximum & Average & Standard deviation \\
\hline Total performance & 280 & 32 & 156 & 135.78 & 15.177 \\
\hline
\end{tabular}

As seen in Table 5, the average of total performance with the frequency of 280 is 135.78.

\subsection{Inferential findings}

In this section, at first, the normality of the distribution of variables under investigation is evaluated using normality test to use parametric and non-parametric tests for investigating study hypotheses.

\subsection{Kolmogorov-Smirnov test}

Kolmogorov-Smirnov test is used to investigate normality. In this test, the normality of distribution of variables is investigated at level of 0.05 . The rejection of initial hypothesis means the rejection of the normality of distribution of variables.

Table 6. Investigating the normality of staff happiness and its components

\begin{tabular}{|l|c|c|c|c|c|}
\hline & Number & Average & Standard deviation & Statistics & $p$-value \\
\hline Being more active & 280 & 11.74 & 2.956 & 3.633 & 0.061 \\
\hline Social activity & 280 & 10.66 & 2.903 & 5.792 & 0.055 \\
\hline Being productive and doing significant and useful things & 280 & 11.55 & 3.211 & 4.728 & 0.060 \\
\hline Programming & 280 & 11.45 & 3.119 & 3.514 & 0.063 \\
\hline Removing concerns & 280 & 10.53 & 3.185 & 3.552 & 0.062 \\
\hline Decreasing expectation & 280 & 11.16 & 3.092 & 5.387 & 0.057 \\
\hline Optimism & 280 & 11.55 & 3.035 & 2.507 & 0.068 \\
\hline Living in the present time & 280 & 10.80 & 2.698 & 3.396 & 0.064 \\
\hline Training perfect character & 280 & 11.69 & 2.296 & 3.834 & 0.061 \\
\hline Having self-confidence & 280 & 11.78 & 3.065 & 5.114 & 0.059 \\
\hline Close communications & 280 & 10.24 & 3.286 & 3.991 & 0.058 \\
\hline Prioritizing happiness & 280 & 12.41 & 3.006 & 3.154 & 0.064 \\
\hline Social character & 280 & 10.60 & 2.690 & 3.819 & 0.058 \\
\hline Leaving aside negative feelings & 280 & 10.77 & 3.359 & 3.62 & 0.066 \\
\hline Happiness in total & 280 & 156.92 & 34.470 & 3.624 & 0.077 \\
\hline Performance in total & 280 & 135.78 & 15.177 & 3.413 & 0.074 \\
\hline
\end{tabular}

According to Table 6, p-value obtained for organizational happiness and its whole aspects and also the staff performance was obtained higher than 0.05 and consequently, initial hypothesis at level of 0.05 is not rejected. Therefore, the distribution of staff happiness and its components and also staff performance is normal.

\section{Regression}

In order to investigate the effect of independent variable (happiness and happiness aspects) on dependent variable (total 
performance), regression test was used. In this test, initial and opposite hypotheses are as follows:

$$
\left\{\begin{array}{l}
\mathrm{H}_{0}: \beta=0 \\
\mathrm{H}_{1}: \beta \neq 0
\end{array}\right.
$$

In which, $\beta$ is the effect of independent variable on dependent variable. In this test, if initial hypothesis is rejected it can be concluded that independent variable has a significant effect on dependent variable.

\subsection{Investigating the interaction effect of staff happiness and happiness aspects on their performance level}

Table 7. Investigating the relationship of happiness and happiness aspects with total performance

\begin{tabular}{|l|c|c|c|c|c|}
\hline & The sum of squares & Degree of freedom & Square of average & Statistics $F$ & $p$-value \\
\hline Regression model & 31870.547 & 14 & 2276.468 & 16.621 & 0.000 \\
\hline Residual & 32397.724 & 265 & 122.256 & & \\
\hline Total & 64268.271 & 279 & & & \\
\hline
\end{tabular}

According to Table 7, p-value was obtained lower than 0.05 and consequently, initial hypothesis at level of 0.05 is rejected. Therefore, the regression model is significant and there is a significant relation between happiness aspects of Ahvaz Imam Khomeini Hospital employees and their performance level.

Table 8. Investigating the effect of happiness aspects on total performance

\begin{tabular}{|l|c|c|c|c|c|}
\hline & \multicolumn{2}{|c|}{ Non-standard coefficients } & Standard deviation & \multirow{2}{*}{ Statistics t } & \multirow{2}{*}{ p-value } \\
\cline { 2 - 5 } & $\mathrm{B}$ & Standard error & Beta & & \\
\hline Constant amount & 101.279 & 3.978 & - & 25.460 & 0.000 \\
\hline Being more active & 2.090 & 0.521 & 0.411 & 4.013 & 0.000 \\
\hline Social activity & 1.729 & 0.572 & 0.331 & 3.022 & 0.003 \\
\hline Being productive & 0.517 & 0.748 & 0.109 & 0.691 & 0.490 \\
\hline Programming & 0.776 & 0.531 & 0.160 & 1.463 & 0.145 \\
\hline Removing concerns & 0.704 & 0.441 & 0.148 & 1.596 & 0.112 \\
\hline Decreasing expectation & 3.910 & 0.681 & 0.797 & 5.737 & 0.000 \\
\hline Optimism & 2.359 & 0.945 & 0.472 & 2.496 & 0.013 \\
\hline Living in the present time & 0.92 & 0.572 & 0.164 & 1.609 & 0.109 \\
\hline Training perfect character & 2.319 & 0.730 & 0.351 & 3.178 & 0.002 \\
\hline Having self-confidence & 2.219 & 0.387 & 0.448 & 5.730 & 0.000 \\
\hline Close communications & 0.112 & 0.629 & 0.24 & 0.178 & 0.859 \\
\hline Prioritizing happiness & 0.563 & 0.414 & 0.111 & 1.357 & 0.176 \\
\hline Social character & 1.761 & 0.799 & 0.312 & 2.204 & 0.028 \\
\hline Leaving aside negative feelings & 1.104 & 0.593 & 0.244 & 1.860 & 0.064 \\
\hline
\end{tabular}

As seen in Table 8, in cases that p-value is lower than 0.05 , initial hypothesis is rejected at the level of 0.05 . Thus, there is a positive significant relationship between being more active, social activity, decreasing expectations, optimism, perfect character, having self-confidence, and social character of Ahvaz Imam Khomeini Hospital employees with their performance. Therefore, with enhancement of social activity up to 0.3 , optimism, perfect character, being more active, decreasing expectations, having self-confidence, and social character are increased $04,0.3,0.4,0.7,0.4$, and 0.3 of a unit of staff performance, respectively. In other words, after investigating the interaction effect of happiness components on staff performance using multivariate regression test it was determined that mentioned components are as better predictor of staff performance.

\section{Discussion and Conclusion}

This research was done to investigate the relationship between happiness and performance of 280 staff in clinical and para-clinical fields of Ahvaz Imam Khomeini Hospital and their performance. The results showed that regression model is significant and there is a significant relationship between happiness and happiness aspects of Ahvaz Imam Khomeini Hospital employees and their performance. Results showed that there is a positive significant relationship between aspects of being more active, social activity, decreasing expectations, optimism, perfect character, having self- 
confidence, and social character of Ahvaz Imam Khomeini Hospital employees and their performance. Therefore, with enhancement of social activity up to 0.3 , optimism, perfect character, being more active, decreasing expectations, having self-confidence, and social character are increased $04,0.3,0.4,0.7,0.4$, and 0.3 of a unit of staff performance, respectively. In other words, after investigating the interaction effect of happiness components on staff performance using multivariate regression test it was determined that mentioned components are as better predictor of staff performance. These findings can be consistent with the results of Suphaphun (2014) and Proctor (2014). Lee Bark and Stanly Tun (2002) based on their studies about the mechanism of effectiveness of happiness on staff performance reported that psychological effects resulted from laughing, act exactly in reverse direction of mental stress so that some people knew laughing loudly for ten minutes equal to two calm sleep. The results of Die et al. that recognized the effective factors on staff performance in transportation companies in Australia showed that happiness of employees had more effect on staff performance with respect to the other factors and had a great impact on productivity and efficiency and finally organizational performance. Alipour and Erabi in 2011 reported that more happiness of employees is accompanied by their more job satisfaction and studied have shown that job satisfaction is accompanied by staff performance improvement in the organization that these results are consistent with the results of the present study. However, researchers have faced with some restrictions such as accessing to world new results, questionnaire distribution, collecting it, and etc in doing their studies, but research restrictions can be merely considered in generalizing results and findings of this study to the other organizations especially hospitals in aspect of doing research. This research was performed using a quantitative method and utilizing the questionnaire. It is suggested that a research can be done on employees through a qualitative method and by interviewing and its results can be compared with the results of the present study. In this study, employees of clinical and para-clinical fields in Ahvaz Imam Khomeini Hospital were studied. It is proposed that a research in wider level can be performed in whole hospitals available in Ahvaz and the other cities of the country. Also, it is suggested that such a research can be done in the other governmental and non-governmental organizations in the country and its results can be compared with the results of the present study.

\section{References}

Argyle, M‘, \& Lu, L ‘(2001) ،The psychology of happiness ‘London :Rutledge.

Baseri, A, (2010), The role of happiness and happiness development in enhancement of epic spirit, Journal of Military Psychology.

Boehm.K.J \& Lyubomirsky.S (2007), " Does happiness promote career Success ?" , Journal of career assessment , vol.16,no.1,pp.101116.

Byars, L.I \& Rue, L.W. (2008). Human Resource Management: 9 th Edition. New York: Mc GrawHill.

Fordyce, M. (1997). Educating for happiness. Ravu Quebecoise De Psyhology , 18, p. 2.

Fordyce MW. (1983).A program to increase happiness: Further studies. Journal of Counseling Psychology.;30(4):483.

Jazani, N., (2008), The management of human sources, Nei Publication, $2^{\text {nd }}$ Edition, Tehran.

Kalayanee S., Anusorn S.,(2014). Happiness in Thailand: The Effects of Family, Health and Job Satisfaction, and the Moderating Role of Gender. Re-examination of Development Policy from Happiness Study . avilable at: http://repository.ri.jica.go.jp/dspace/ handle/10685/251

Luma, D., Katler, H.C., (2003), the art of happiness, translated by Rafiee, Ch., $2^{\text {nd }}$ Edition, Tehran: Tandis Bookstore.

Pahlevan Sadegh, A, Bakhtiar Nasrabadi, H.A., (2009), Educating the Fordyce's happiness model and its effect on enhancement of happiness in Martyrs and Veterans families, Journal of Behavior, 16 ${ }^{\text {th }}$ year, No. 84, pp. 35-46.

Proctor C., (2014). Effective Organizational Communication Affects Employee Attitude, Happiness, and Job Satisfaction. A Thesis submitted to Southern Utah University In partial fulfillment of the requirements for the degree of Master of Arts Professional Communication. Available at : https://secure.suu.edu/hss/comm/masters/capstone/thesis/proctor-c.pdf

Sharifi Kh, Souki Z., Tagharrobi, Z., Akbari H., (2010), The status of happiness and its related factors among students of Kashan University of Medical Sciences, during 2006-2007, 14(1), pp. 62-69.

Suphaphun W., Sakulkoo S., Tubsree C. (2014). Happy workplace: A study of a selected company in Amata Nakorn Industrial Estate, Thailand. HRD JOURNAL p.p.: 92-104.

Tripi, M.M., (2005), The necessity of creating happiness in organizations, translated by Rezaei, Ahmad Ali, Journal of Management, No. 105-106,

Zarei, M.H., Jandaghi, Gh., Haghgouyan, Z., (2009), Recognizing the happiness components in workplace and assessing the status of these components in executive organizations in Qom province, Governmental Management, 1(2), pp. 35-48.

Zahedi, Sh., Rafiee, M., (2011), Investigating the relationship between human resource strategy and ethical decision making strategy with organizational performance: a research in research organization of Ministry of Agriculture, General Management Research, 4(13), pp. 5-24. 